Two dietary factors have been implicated in the parallel aging of tendons and arteries. Schwartz ${ }^{2}$ suggests that the trace element silicon is the factor in dietary fibre and hard water which reduces the incidence of CHD. Silicon contributes to the stability of connective tissue by forming -O-Si-O- bridges. Ascorbic acid is the second factor. Its role in collagen synthesis ${ }^{3}$ makes it essential for both tendons and arteries.

Our observations on cardiac patients who take up marathon running show a conspicuous increase in silicon-rich foodstuffs (pectin, bran, and alfalfa) and also ascorbic acid (fresh fruit and vitamin $\mathrm{C}$ supplements). The longest run for cardiac patients is the Primo $100-\mathrm{km}$ run on the island of Oahu. It is supported by the cardiac rehabilitation programme of the Honolulu YMCA. The event is social and non-competitive.

In our view any dietary manipulation should be aimed at increasing "distance covered on foot."

$$
\begin{array}{r}
\text { T J BASSLER } \\
\text { Editor, } \\
\text { American Medical Joggers }
\end{array}
$$$$
\text { Association }
$$

Department of Pathology,

Centinela Hospital,

Inglewood, California

'Adams, C W M, et al, Atherosclerosis, 1974, 19, 429. Schwartz, K, Lancet, 1977, 1, 454.

3 Turley, S D, et al, Atherosclerosis, 1976, 24, 1.

\section{Paget's disease of bone}

SIR,-Your leading article (4 June, p 1427) dismisses glucagon and mithramycin in the treatment of Paget's disease of bone because of disadvantages which were not enumerated.

The dose of mithramycin used by Ryan et al was $25 \mu \mathrm{g} / \mathrm{kg} /$ day and was reduced below this only for elderly patients and those with side effects. If the dose of mithramycin used is $15 \mu \mathrm{g} / \mathrm{kg} /$ day patients respond clinically and biochemically and no anorexia, nausea, vomiting, drowsiness, fever, thrombocytopenia, or hepatic damage is encountered. ${ }^{2}$ A dose of $10 \mu \mathrm{g} / \mathrm{kg}$ is also effective. I know of no reports of the use of oral cytotoxic drugs in patients with Paget's disease of bone, but a number of years ago I had the opportunity of observing the effect of azathioprine $50 \mathrm{mg} /$ day for three weeks given to a patient who happened to have Paget's disease of bone. There was no relief of bone pain but both serum alkaline phosphatase and urinary hydroxyproline levels fell gradually. Paget's disease of bone is a relatively common disorder and clinicians should from time to time have opportunities to observe the response of the bone disorder to oral cytotoxics given for other reasons.

Glucagon when given intravenously or subcutaneously is remarkably free of side effects. The only problem encountered in the frequent use of the drug over seven years ${ }^{34}$ has been nausea and vomiting, which occurs when large doses of the hormone are given by intravenous infusion. These symptoms are dose-dependent and are rapidly relieved by stopping the infusion for a few minutes, glucagon being rapidly cleared from the blood. ${ }^{5}$ Glucagon when given intravenously at a dose of $8-10 \mathrm{mg} /$ day results in relief of bone pain and a fall in serum alkaline phosphatase and urinary hydroxyproline levels within 10 days. A similar clinical and biochemical response takes many months with calcitonin.

The patient with Paget's disease of bone can be maintained on subcutaneous glucagon
2-3 mg once or twice daily without side effects. Alternatively glucagon can be given in combination with calcitonin and I hope to publish further data on this variation of therapy in due course. Glucagon may actually have some advantages over the calcitonins. Hypocalcaemia is uncommon during glucagon therapy and the hormone may be less likely to give rise to antibodies. Furthermore, I have not encountered a patient with Paget's disease of bone who was resistant to glucagon therapy.

JOHN R CONDON

Department of Medicine,

Brook Hospital,

London

Ryan, W G, Schwartz, T B, and Northrop, G, Seminars in Drug Treatment, 1972, 2, 57. Condon, J R, et al, British Medical fournal, 1971, 1, Condon, J R, British Medical fournal, 1971, 4, 71

Condon, J R, Knight, M, and Day, J L, British fournal of Surgery, 1973, 60, 509 .

Assan, R, Tchobroutsky, G, and Gross, G, Abstract submitted to the meeting of the European Association for the Study of Diabetes, Southampton,
September 1971 .

\section{Psychotropic drugs and road accidents}

SIR,-Your leading article (11 June, p 1492) "Deaths due to drug treatment" made no mention of one possible lethal consequence of drug treatment: road traffic injury. The relationship between the taking of drugs and subsequent accidental injury or death is a field which has attracted little interest or research effort to establish the facts. This is surprising in view of the importance of the matter.

In 1970 in the USA Kibrick and Smart ${ }^{1}$ reported that $11-15 \%$ of accident-involved drivers had taken a psychotropic drug before the accident. A report of the Medical Commission on Accident Prevention ${ }^{2}$ has reviewed the present situation and summarised the scanty amount of information which has accumulated since Kibrick and Smart published their findings. This report states that "doctors must constantly bear in mind the possibility of adverse drug effects on driving and much will therefore depend upon the information which is available to doctors on this important subject. Unfortunately . . . information about the effects of drugs on driving behaviour is extremely hard to obtain."

The situation as regards the effects of psychotropic drugs and other medications on driving behaviour is certainly complex and little is known with certainty. Clayton ${ }^{3}$ states that "the role of psychotropic drugs in the causation of driving accidents remains unclear and will remain so until carefully controlled large-scale field studies are undertaken." There is little hard evidence that the acute consumption of a drug with a sedative effect may adversely affect skill in driving and there is practically no knowledge of the effects of chronic consumption of such drugs on driving or other activities requiring a high degree of motor co-ordination and judgment. Yet the evidence incriminating alcohol consumption in impairment of ability to drive is now overwhelming and the response of society to this evidence has been the introduction of the breathalyser.

Sedative drugs, of course, are not detected in the breathalyser and if they were there would be no legal implications. Yet there is good evidence that the sedative drugs commonly prescribed (previously the barbiturates and now the benzodiazepines) do potentiate the effect of alcohol. A standard work on the side effects of drugs" states that "diazepam has a tendency to produce drowsiness and ataxia. ... There is a summation effect with alcohol: patients should be warned to be very moderate with alcohol and to take none before driving."

Prescriptions for sedative drugs and hypnotics now run into millions a year. The people to whom they are prescribed are also likely to be using alcohol, perhaps in unaccustomed amounts; yet there is no requirement placed upon the medical profession to issue a warning of this interaction effect when the drugs are prescribed.

We believe that research in this field has been too long delayed and that it should now be accorded priority. Until such time as definite information is available to guide doctors we consider that it should be made obligatory to issue warnings of interaction effects with alcohol whenever sedative drugs are dispensed. Complaints may be made that issuing such warnings and recommendations will inevitably decrease treatment compliance, but if this is to be set against the potential saving of life then the balance will be favourable, for sedative drugs are frequently prescribed for relatively trivial reasons. If the concealed dangers were to be forcibly pointed out to patients and to doctors, then it would increase the chances that they are only prescribed for, and taken by, those patients who really need them.

R P SNAITH

Departments of Psychiatry

and Psychology,
University of Leeds

Drug Information Centre, IAN HINDMARCH

St James's Hospital

Leeds

' Kibrick, E, and Smart, R G, fournal of Safety Research, 1970, 2,73.

Drugs and Medicines (reprinted from Medical Aspects
of Fitness to Drive, 3rd edn). London, Medical Commission on Accident Prevention, 1976.

3 Clayton, A B, Human Factors, 1976, 18, 241 .
- Meyler, L, and Herxheimer, A, Side Effects of Drugs, Meyler, L, and Herxheimer, A, Side Effects of
vol 7. Amsterdam, Excerpta Medica, 1972.

\section{Abdominal tuberculosis in Britain}

SIR,-Your leading article (18 June, p 1557) reminds us that abdominal tuberculosis still occurs in the indigenous population of the United Kingdom. Gynaecologists would do well to recall its possibility, particularly in Asians but also in other races. Four cases have been seen in a short personal experience in the West Midlands. The fourth and most recent one illustrates how difficult it can be to establish the diagnosis, however great the clinical suspicion.

An Asian woman, 22 years of age, was seen at the 30th week of her first pregnancy because the uterus was larger than expected. An $x$-ray of the abdomen confirmed the presence of twins. The patient was admitted to hospital because she looked ill and weighed only $44 \mathrm{~kg}$. The haemoglobin concentration was $12.3 \mathrm{~g} / \mathrm{dl}$ and the chest $x$-ray normal Labour started spontaneously at the 35 th week and she was delivered of living twins $(1.68 \mathrm{~kg}$ and $1.75 \mathrm{~kg}$ ). Within $48 \mathrm{~h}$ pyrexia with marked tachycardia developed and anaemia, jaundice, and hepatomegaly followed. The haemoglobin fell to $8 \cdot 1 \mathrm{~g} / \mathrm{dl}$ with $8.6 \%$ reticulocytes and the urine was free of bile. The plasma albumin concentration fell to $25 \mathrm{~g} / \mathrm{l}$ and that of globulin rose to $38 \mathrm{~g} / \mathrm{l}$, while the alkaline phosphatase activity rose to 95 King Armstrong units. A pure growth of Escherichia coli was obtained from the urine and a high vaginal swab. Initial blood cultures were sterile. Antibiotic therapy was commenced. By the 10th day the 